\title{
Formulating the efficacy of using diagnosis to conceptualise distress.
}

\author{
Rebecca Regler* \\ Independent Scholar, UK
}

\begin{abstract}
Is diagnosis the most effective way of conceptualising distress? This paper explores ideas around the use of diagnosis and alternative methods of conceptualising distress. It describes the function of diagnosis, the experience of being diagnosed and the challenges it can present. It also considers the influence which neoliberalism has had upon the mental health system. Psychological formulation has gained momentum as an alternative approach to understanding mental health difficulties. It is suggested that this may be a way forward alongside using a holistic traumainformed model to gain a better understanding of distress.
\end{abstract}

Keywords: Distress, Neoliberalism, Mental health, Trauma.

Accepted on March 20, 2018

\section{The Function of Diagnosis}

Society has a long history of conceptualizing psychological distress as medical illness which can be traced back as far as Hippocrates (460-377 BC) and was formalized with the development of the first edition of the Diagnostic and Statistical Manual (DSM) in 1952 [1]. There are many benefits to understanding psychopathology using the method of diagnosis but also some draw backs. Firstly, it provides a framework for understanding patterns of behavior or 'symptoms' by collating common experiences [2]. This can enable an individual to feel safe and validated within the knowledge that they are not the only person to have had the experience. Secondly, it provides information about etiology and prognosis and importantly access to treatment. In order to access treatment a formal diagnosis is often required by meeting the criteria set by the DSM, which is regularly changed and updated [3]. It is important to acknowledge that some individuals find the diagnostic process beneficial, for instance one service user said:

'I do feel relief from having the diagnosis. It's a massive relief to realize that a lot of my behavior is completely normal for a bipolar person' [4].

This particular quote is of interest as it demonstrates the concept of labeling theory. Labeling theory is rooted in symbolic interactionism and theorizes that a label is a primary deviance and secondary deviance is the behavior resulting from the deviant role [5]. For instance, the label of mental illness as primary deviance may lead to a secondary deviance of social exclusion. A self-fulfilling prophecy or 'confirmation biases may occur in which people begin to behave in concordance with the labels assigned to them. In this example we see the diagnosed individual refer to themselves as a 'Bipolar person' and normalize their behavior in accordance with the label they have received. Psychological distress can commonly be misperceived as a character flaw or 'strange' behavior but a diagnosis provides clarity that there is a reassuring explanation for the way they are feeling and behaving [6].

A medical diagnostic system implies there is a certain degree of scientific rigor, however for most mental illnesses there are no routine medical tests which can determine pathology (such as a blood test for neurotransmitter levels) so diagnosis is made using clinical observation instead [6]. Clinical Psychologist Dr. Lucy Johnstone suggests that a circular debate can emerge as a result of subjectivity and the absence of evidence of biological abnormality. For instance, 'Doctor why am I hearing hostile and critical voices?' 'Because you have Schizophrenia', 'Doctor why do I have Schizophrenia?' 'Because you are hearing hostile and critical voices', one confirms the other but it retains subjectivity. However in most (not all) cases of diagnosing a physical illness the debate isn't circular, for instance, 'Doctor, why am I experiencing severe headaches and blackouts?' 'Because the MRI scan showed that you have a brain tumor which is causing your symptoms' [7]. The evidence of biological abnormality is objective as opposed to subjective which becomes even more problematic when we see the social context in which mental illness exists.

\section{Diagnosis Human?}

Critics of psychiatry perceive diagnoses as social constructions resulting in pathologising human distress in the absence of its context $[8,9]$. This could lead to diagnosed individuals feeling alienated and stigmatized because the process of identifying and understanding their distress is directed by others [10]. This has been further exacerbated by the chemical imbalance theory, one that could be remedied by the pharmaceutical industry who could 're-balance' these chemicals with anti-depressant and anti-psychotic medications "like insulin for diabetes" [11]. Eminent Psychiatrist Joanna Moncrieff argues that the evidence that a serotonin imbalance causes depression is of an 'inconsistent and tenuous nature' 
(2006: 301). The British Psychological Society [12] suggests that attributing people's experiences of distress to an illness is inherently flawed as it implies a biological cause. This can overshadow the meaning of precipitating events as being mere 'triggers' to a genetic predisposition or vulnerability which has caused 'symptoms' as opposed to understandable coping strategies as a direct result of adversity. Furthermore, it implies that a treatment aimed at correcting the biological 'imbalance' will result in an improvement of the behaviors or symptoms thus limiting the individuals sense of agency and capacity to use support to overcome the challenges they are facing. This is consistent with the perspective of Sanderson who proposes that:

'Dehumanizing the individual and distorting their reality prevents the individual from legitimising or naming the experience as abuse or trauma' (2013:19).

A study undertaken in Community Mental Health Teams found that there was a widespread use of applying labels to the experiences of distress which was critiqued as biological reductionism. It was proposed that opposed to mental illness, a more appropriate label would be 'diagnosis human' [13]. Boyle [14] asserts that the medicalization of distress places a disproportionate emphasis upon medical terminology which separate life experiences and environmental factors from formulations of 'madness'.

\section{The Social Model of Disability}

Historically the medical model of disability and illness appeared widely accepted by society. This became contested when disability campaigners challenged the concept that their disabilities were caused by individual invalidity and proposed a social model which theorizes the cause as oppression within society. The social model has grown in integrity following the work of Finkelstein [15], Barnes [16] and Oliver [17-19]. The distinction between individuals considered to have a socially accepted response to stressors and those who become pathologised is often shaped by politics, power and inequality. For instance, 'Battered Woman Syndrome' was considered to be a valid diagnosis up until the fourth edition of the DSM [3]. This highly controversial, stigmatizing and discriminatory term was used to pathologise the behavior of women following domestic abuse despite having scarce psychiatric validity which was loosely associated with psychological theories of 'learned helplessness' [20]. The idea of 'Battered Woman Syndrome' locates the problem within the survivor of the abuse as opposed to the abuser, sometimes this can happen with survivors of sexual abuse as well;

'I cannot understand how the vast majority of perpetrators of sexual violence walk free in society; whilst people who struggle to survive its after effects are told they have disordered personalities' [21].

\section{Psychological Formulation}

Perhaps an area which requires further narrative qualitative research is whether the process of psychological formulation can bring about a similar sense of relief and understanding which diagnosis potentially provides. Harper and Moss [22] define psychological formulation as 'a process of on-going collaborative sense-making'. The collaboration used in a formulation is inherently different to the act of being diagnosed by an expert physician. Psychological formulation can be traced back to the 1950 s which was also when the first DSM was published. Interestingly mental illnesses were described as 'reactions' to the environment or adversity within this first edition which would now perhaps be considered more of a psychological than psychiatric approach [11]. However the concept of reactions was removed in the second edition and a more medical approach was adopted. Whilst a medical diagnosis is aided by tools and questionnaires and quantified using either the DSM or the International Classification of Diseases, psychological formulation is yet to be stratified in such a way.

The British Psychological Society has produced guidance for Clinical Psychologists to use in their professional practice [12] which seeks to define formulation and outline its process. However, formulation is not a protected term so therefore it can be used by other professionals such as Psychiatrists who can use an abbreviated version alongside diagnosis or Psychological Wellbeing Practitioners within 'Improving Access to Psychological Therapies' services who are not as highly trained as Clinical Psychologists. This means there can be a great variation in the experience of formulation for service users which could be unhelpful. Whilst formulation has the potential be a transformative therapeutic process for the individual it may be hard to translate this into future care and knowledge for other professionals to understand. Without a categorization process such as a diagnostic code, how can formulation be understood not only by other professionals but also by social security or insurance systems?

\section{The Impact of Neoliberalism}

With the ever increasing influence of neoliberalism on modern health and social care it seems more important than ever for patients' qualitative experiences to be quantified and measured. The growing ideology of marketization within statutory mental health services has resulted in the recent implementation of 'Payment by Results' which includes a method of 'Clustering'. Practitioners categorize patients into 'clusters' divided by diagnosis and impact upon daily functioning and are then required to reduce their symptoms through treatment. If the service achieves their targeted outcomes they will be financially compensated [13]. The power and influence held by the pharmaceutical industry is also an important factor in the medicalization of distress within a capitalist society. Pharmaceuticalisation is defined as the 'translation or transformation of human conditions, capabilities and capacities into opportunities for pharmaceutical intervention' [23]. One example of this could be the widespread use of Ritalin as a treatment for 
the contested diagnosis of Attention-Deficit Hyperactivity Disorder [24].

\section{The Link between Trauma and Mental Health}

'An important question in mental health shouldn't be 'What is wrong with you?' But rather 'What's happened to you?' [7]

There is a growing field of research which demonstrates correlations between trauma, adversity, inequality and mental illness. The ACEs (Adverse Childhood Experiences) study [25] researched over 17,000 Americans and is considered to be a groundbreaking seminal piece of epidemiological research which has had a significant influence over mental health research and policy. The study demonstrated that the more adverse events an individual experiences before the age of 18 , the more likely they are to experience poor mental health. This evidence was further compounded by Dillon et al. [7] who state that the frequency, severity and range of adverse experiences have a dose dependent relationship with the impact it has upon an individual's mental health. A systematic review of 33 worldwide studies by Mauritz et al. [26] estimated that around half (47\%) of those with severe mental illness had experienced physical abuse and around a third (37\%) had experienced sexual abuse. An even higher prevalence was found in a study of individuals diagnosed with Borderline Personality Disorder in which $88 \%$ reported childhood emotional abuse, 65\% physical abuse and 56\% sexual abuse [27]. This yielded similar results to study by a Herman et al. [28] of Borderline Personality Disorder in which $71 \%$ reported physical abuse and $68 \%$ sexual abuse. Further to the evidence for trauma, inequality also has a significant impact as demonstrated by Wilkinson and Pickett [29] who found that the more unequal a society is, the higher the rates of mental illness are. Furthermore, poverty is considered to be a strong predictor for mental illness because of its interrelation to so many other causative factors [30].

\section{A Paradigm Shift?}

Dillon et al. [7] propose that there is a 'strong evidence based synthesis of findings from trauma studies, attachment theory and neuroscience, which offers new hope for recovery' (2012: 145). They propose that systemic change could be achieved in the way of a 'paradigm shift' towards an integrated, holistic trauma-informed model showing that mental distress is better understood as an understandable reaction to trauma as opposed to an illness. The trauma genic neurodevelopmental model of Read et al. [31] includes important evidence which demonstrates that stress causes measurable neurological changes in the brain such as changes in dopamine and serotonin levels. This builds upon the commonly accepted 'bio-psycho-social' etiology model by explaining how social circumstances and adversity can lead to psychological and biological reactions. Although the neuroscientific evidence is modern, the concept of reactions in Psychiatry is around 65 years old [11].
Despite all of this overwhelming evidence, the focus remains upon the pathology of the individual and the need to 'fix them' rather than addressing the structural inequality and adversity within society. As stated by the philosopher May [32] 'it is no measure of health to be well adjusted to a sick society'. It has been suggested that an over-reliance upon psychological approaches tend to focus upon individual pathology and the phenomena of 'case-ism' leads to locating the source of an individual's distress within them as a deficit whilst simultaneously ignoring the context of oppression and poverty $[33,34]$. The user movement (individuals with mental illness) has highlighted a need to move away from 'symptom management' and towards what recovery actually means in terms of improving quality of life [35]. May [32] states that in his clinical practice he feels that rather than fitting people's experiences into a diagnostic category, it is more important to help people describe and understand their experiences in their own terms.

As with other socially constructed phenomenon, labeling individuals serves a function otherwise it would not persist. Perhaps this is because it is easier to diagnose an individual as being unwell than diagnosing a whole country as being unequal and to start addressing the prevalence and impact of trauma. It is clear that change in Psychiatry is needed but exactly what change and how it will be achieved is not clear. Both systems of diagnosis and psychological formulation have positive and negative aspects to them. It seems that psychological formulation as a process is not yet rigorous enough to be a replacement for diagnosis and it doesn't easily fit into the social systems in the same way as a medical diagnosis can. The paradigm shift proposed by Dillon et al. [7] towards a holistic trauma-informed system could become a viable alternative to diagnosis. In the meantime, psychological formulation could form a useful adjunct alongside diagnosis, to help re-balance the dominant biomedical imbalance.

\section{References}

1. Read J, Sanders P. A straight talking introduction to the causes of mental health problems. Ross-on-Wye. PCCS Books. 2010.

2. Tew J. Social approaches to mental distress. Basingstoke. Palgrave Macmillan. 2011.

3. American Psychiatric Association (APA). Diagnostic and Statistical Manual of Mental Disorders ( $5^{\text {th }}$ edn) Arlington. VA: American Psychiatric Publishing. 2013.

4. Owen S, Saunders A. Bipolar disorder: The ultimate guide. Oxford: one world publications. Kindle Edition. 2011.

5. Becker H. Outsiders: Studies in the Sociology of Deviance. New York. Free Press. 1973.

6. Craddock N, Mynors-Wallis L. Psychiatric diagnosis: impersonal, imperfect and important. Br J Psychiatry. 2014;204:93-5. 
7. Dillon J, Johnstone L, Longden E. Trauma, dissociation, attachment and neuroscience: a new paradigm for understanding severe mental distress. J Crit Psychol Counsel Psychother. 2012;12(3):145-55.

8. Bracken P, Giller J, Summerfield D. Psychological responses to war and atrocity: The limitations of current concepts. Soc Sci Med. 1995;40:1073-82.

9. Davis H. The psychiatrization of post-traumatic distress: Issues for social workers. Br J Soc Work. 1999;29(5):75577.

10. Humphreys C, Joseph S. Domestic violence and the politics of trauma. Women's Studies International Forum. 2004;27(5-6):559-70.

11. Whitaker R, Cosgrove L. Psychiatry under the influence; institutional corruption, social injury and prescriptions for reform. New York. Palgrave Macmillan. 2015.

12. Division of Clinical Psychology. Good practice guidelines for the use of psychological formulation. Leicester. British Psychological Society. 2011.

13. Moth R. Diagnosis human: Markets, targets and medicalisation in community mental health services. In: Weinstein J, Ferguson I, Lavalette, M (eds) Mental Health: Critical and Radical Debates in Social Work. Bristol: Policy Press. 2014;57-61.

14. Boyle M. Making the world go away and how psychology and psychiatry benefit. In: Rapley M, Dillon J (eds) Demedicalizing Misery: Psychiatry, Psychology and the Human Condition. Basingstoke. Palgrave Macmillan. 2011;27-43.

15. Finklestein V. Attitudes and disabled people: Issues for discussion. New York. World Rehabilitation Fund. 1980.

16. Barnes C. Disabled people in Britain and discrimination: A case for anti-discrimination legislation. London. Hurst \& Co. 1991.

17. Oliver M. The politics of disablement. London. Macmillan. 1990.

18. Oliver M. Understanding disability: From theory to practice. London. Macmillan press. 1996.

19. Oliver M. The social model of disability: Thirty years on. J Disabil Soc. 2013;1:14.

20. Rothenberg B. The success of the battered woman syndrome: An analysis of how cultural arguments succeed. In sociological forum. 2002;17(1):81-103.

21. Shaw C, Proctor G. Suzi's story. Asylum (Special Edition Women at the Margins). 2004;14(3):11-13.

22. Harper D, Moss D. A different kind of chemistry? Reformulating formulation. Clin Psychol. 2003;25:6-10.

23. Williams S, Martin P, Gabe J. The pharmaceuticalisation of society? A framework for analysis' in sociology of health and illness. 2011;33(5):710-25.
24. Rogowski S. Critical social work with children and families: Theory, context and practice. Bristol. Policy Press. 2013.

25. Felitti VJ. Relationship of childhood abuse and household dysfunction too many of the leading causes of death in adults: The adverse childhood experiences (ACE) study. Am J Prev Med. 1998;14(4):245-58.

26. Mauritz M, Goossens P, Draijer N, et al. Prevalence of interpersonal trauma exposure and trauma-related disorders in severe mental illness. Eur J Psychotraumatol. 2013;4.

27. Merza K, Papp G, Kuritárné Szabó I. The role of childhood traumatization in the development of borderline personality disorder in Hungary. Eur J Psychiatr. 2015;29(2):105-18.

28. Herman JL, Perry JC, Van der Kolk BA. Childhood trauma in borderline personality disorder. Am J Psychiatry. 1989;146(4):490-5.

29. Wilkinson R, Pickett K. The spirit level: Why equality is better for everyone. London. Penguin Books. 2010.

30. Read J. Can poverty drive you mad? Schizophrenia, socioeconomic status and the case for primary prevention. $\mathrm{N} \mathrm{Z}$ J Psychol. 2010;39(2):7-19.

31. Read J, Perry B, Moskowitz A, et al. The contribution of early traumatic events to schizophrenia in some patients: A traumagenic neurodevelopmental model. Psychiatry. 2001;64(4):319-45.

32. May R. Working outside the diagnostic frame. Psychologist. 2007;20(5):300-1.

33. Gross JJ. Emotion regulation in adulthood: Timing is everything' in current directions in psychological science. Curr Dir Psychol Sci. 2001;10(6):214-9.

34. Ferguson I, Woodward R. Radical social work in practice: Making a difference. Bristol. The Policy Press. 2009.

35. Repper J, Perkins R. Social inclusion and recovery: A model for mental health practice. London. Bailliere Tindall. 2003.

\section{*Correspondence to:}

Rebecca Regler Independent Scholar, UK

Tel: +44 1865270000

E-mail: rebecca_regler@outlook.com 